\title{
The Effects of Providing Surgical Progress Information Using SMS on Satisfaction of Nursing Needs and State Anxiety of the Patients' Family
}

\author{
Kim Jeoung $\mathrm{Mi}^{1}$, Vasuki $\mathrm{R}^{2}$ \\ 1,2 (Department of Nursing/ KAYA University, South Korea)
}

\begin{abstract}
The aim of this study was to provide information on the progress of surgery through SMS to the family members of orthopedic surgery patients and to confirm the effect of state anxiety and nursing needs and satisfaction on the patient.

Methods: The study focused non-equivalent control group non-synchronized research design. Data were collected from April $1^{\text {st }}$ to June 30th on 2016 at D hospital in B City. The study includes 48 family members as control group (24 subjects) and experimental group (24 subjects). Satisfaction of nursing needs was measured with the questionnaire on the needs of operation patients 'families and anxiety was measured with the state anxiety scale. Collected data were analyzed using SPSS 12.0. The subjects 'general characteristics were analyzed through real numbers and percentages, the homogeneity of the two groups was tested through $\chi 2$ test and t test, the reliability of the measuring tools was tested through Cronbach's a, and the hypotheses were tested through t test by using SPSS/WIN 21.0 program.

Results: Hypothesis 1: The difference of the state anxiety scores before and after the intervention was $5.332 \pm$ 8.76 in the experimental group and $7.58 \pm 10.89$ in the control group $(t=-0.526, p=.572)$, and the first hypothesis was rejected. Hypothesis 2: hypothesis 2 was supported because there was a statistically significant difference ( $t=5.482, p<.001)$ in the difference of satisfaction score of nursing requirement after intervention between $3.32 \pm 0.42$ points in the experimental group and $2.43 \pm 0.61$ points in the control group.

Conclusion: the results of the study into consideration, that providing information by using SMS about surgical progress was an effective in order to reduce the anxiety of family members of patients undergone surgery. Therefore, the study suggests that, the same study would be conduct by various communication media and different surgical settings in order to compare the effectiveness.
\end{abstract}

Keywords: SMS, Anxiety of patient's family, surgical patient, nursing needs and satisfaction

\section{Introduction}

The surgical waiting room can be an area of uncertainty, stress, and frustration. The hospital staff views surgery and its components as a nonthreatening, everyday occurrence. However, the surgical environment is unfamiliar for families and creates an atmosphere of fear and anxiety. Insufficient information is the cause of surgical waiting room uncertainty. Notifying the surgical patient's family member of the patient's progress is significant because the delay of information increases the family member's anxiety. Anxiety translates to decreased family member satisfaction and increased frustration (Muldoon, Cheng, Vish, DeJong, \& Adams, 2011)., surgery can lead to various negative experiences such as uncertainty about surgery, fear of anesthesia and death, fear of postoperative pain or complications, in addition to the economic burden on the patient and family (Hong, Hee-jung, 2004). Leske (1996) suggested that the waiting period during surgery is the time when anxiety is the highest for family members. Leske (1995) found that family members who received intraoperative reports were less anxious than those who did not receive reports. The family of surgical patient, while waiting experiencing moderate concept of time, feeling the collapse of daily life, feeling alienated, Anxiety until the patient come out of surgical room, it can be transferred to the patient, it may lead negative impact on patient recovery and adjustment (Park, 2002).

In addition, several studies (Park, 2002; Hong, Hee-jung, 2004; Lim Jung-soon, Jung Bok-ryeo, 2006) have reported that the anxiety of the family members who provided surgery information to the family members and supports the need for nursing interventions for family members. Surgical patient family members' anxiety may lead to patient dissatisfaction, which is an important quality indicator (Kelly, 2011)This study included consistent surgical patient information provided at regular surgical progress using SNS to decrease the surgical patient's family member's anxiety. One of the challenges in communication is consistency (Nursing, 2008). MacDonald, Latimer, and Drisdelle (2006) surveyed what was helpful to families while their relative was in surgery. Communication was at the top of the list. MacDonald et al. discovered that a surgical liaison nurse provided the necessary information and acted as a support mechanism for the surgical patient's family to decrease anxiety. Researchers in the University of Virginia Health System (as cited in Nursing, 2008) found that 
updating a patient's family members every 2 hours with a phone call provided comfort. (Titler, 2010) suggested adopting two and sustaining a new procedure is necessary for success. Leske et al. (1996) reported that during the operation to reduce the anxiety of surgical patients, the patient's recovery status improved as a result of informed support, and the patient family was also mentally supported and helped the patient to adjust to the treatment process. By using various telecommunication media are used for accurate information delivery to the patient's family. Medias such as include printing material, natural and artificial models, audio video media like computers etc (Yu, 2003). As a means of communication, the mobile phone has become a part of familiar communication environment, and mobile phone and Internet messenger service become generalized, and text message becomes universal media (Kwon \& Hwang, 2004).

Notifying the surgical patient's family member is important because the delayed information may increase the family member's anxiety. Anxiety translates to decreased satisfaction, and increased frustration and stress (Muldoon et al., 2011). Boyle, (2005), shows patient advocacy to be an important factor in the surgical experience. It is important that the patient, as well as the family, knows the commitment of the perioperative nurse during a time when the patient is under anesthesia and vulnerable. Benko, (2001) shows the importance of patient satisfaction through receiving an extra measure of care. Both of these studies focus on patient satisfaction through decreasing anxiety of the patient and the family member. Lee (2009) reported in previous study using text messaging in Korea, that providing information on the progress of surgery using text messages were an effective nursing intervention for relieving anxiety of patient's family members.

The Joint Commission (2014) has new standards for communication that are intended to ensure that health care providers communicate effectively with patients. The Joint Commission bases its actions on research that indicates an association between poor communication, negative health outcomes, and increased cost (Blackstone, Garrett, \& Hasselkus, 2011). The use of the proving information through SMS may improve communication with surgical patient's family members and reduce their anxiety. Therefore, it is necessary to increase the utilization of SMS in the education of the target person or the family in the medical institution, and to provide detailed information about progress of the operation and the patient's condition using the SMS for improving the satisfaction of the nursing demand and reducing the anxiety of the surgical patient's family members respectively.

\section{The purpose of this study}

The purpose of this study was to investigate the effectiveness whether the surgical patient's family member's anxiety was reduced by increasing communication in a timely and consistent manner using SMS to update the surgical patient's family members of the patient's surgical progress.

\section{Research hypothesis}

1. The experimental group receiving the SMS about the progress of the surgery would have a lower anxiety score than the control group not receiving the information.

2. The experimental group receiving the SMS about the progress of the surgery would be more satisfied with the nursing needs than the control group who did not receive the information

\section{Operational definitions}

\section{i. State anxiety}

State anxiety is defined as an unpleasant emotional arousal in face of threatening demands or dangers. (Spielberger, 1972, 1983). In this study, Spielberger's state anxiety scale was used to measure family of surgical patient's anxiety by using a tool developed by Kim, Jeong-Taek and Shin Dong-Kyun (1978).

\section{ii. Nursing needs satisfaction}

Nursing needs and satisfaction has been found to be related to performance within the work setting (Landeweerd and Boumans, 1988), Lee (2006) explained 'A Study on the Relationship Between Nursing Care Needs and Nursing satisfaction", Journal of Nursing Research and Park (2002) used Perioperative Family Needs Questionnaire(PFNQ) in this study, the tool developed by Carmody (1991).

\section{iii. Providing information}

It is found that the service, which provides (serves) data/knowledge/information somehow.

(Lee \& Suh, 1995) suggested that providing information the progression of patients' surgery by SMS, also described by Hong Hee Jung and Lee Myeong-ae (2000) which patient's family needs to reduce anxiety and meet the needs of them. 


\section{Literature Review}

\section{The effect of providing information on the progress of surgery for the patient's family}

In order to provide various informations for the patient's family, it is suggested to use the audio-visual materials such as tape, educational booklet, and video tape in addition to providing information by the nurse's explanation as a direct information providing method. Mainly by nurses and by phone calls (Park, 2002) reported that the nursing needs and anxiety of the family members of the surgical patients were found to be higher when the anxiety level before, during, and after surgery was higher. Park (2002) reported that nurses' use of pamphlets to provide information to family members waiting in the waiting room while undergoing laparotomy surgery led to increased nursing satisfaction and low level of state anxiety.

On the other hand, it is common for the nurses to explain the information provided by the nurses to the family of surgical patients. However, the education by the print media may be affected by the lack of explanation, the provider's emotional intervention, (Kim, Jung-hee, 2005). In order to compensate for these disadvantages, research on providing nursing information using audiovisual materials such as videotape, 2007; Hong Hee-jung, 2004). In the crisis of surgery, the patient's family wants to continuously listen to the patient's condition. Therefore, the character service, which is one of the indirect information methods, has a disadvantage in that it can only provide a piece of information. However, considering the cost -saving aspect, it may be possible to resolve the desire for information provision of family members of surgical patients to some degree.

\section{Anxiety of family of surgery patients}

Anxiety is a sequence of cognitive, emotional, and behavioral responses to forms of tension that have a common element of perceived threat and arousal (Hong Hee-jung, 2004) as a basic emotional response to an unspecified or unknown threat (Spielberger, 1972). In the case of mild anxiety, the senses become more agile, have no physical symptoms, but rather increase motivation. However, if the anxiety of the severity of the anxiety is experienced, the physical pathology will occur and it should be intervened early (Park, 2002). Surgery causes anxiety for both the patient and the family of surgery patients (Lim Jung Soon, 2006), among which surgery latency causes the greatest anxiety for the surgical patient family (Leske, 1996) (Hong Hee-jung, 2004). (2003) reported that the perceived misunderstanding of relatives and family members about the surgery and anesthesia process as an anxiety factor influenced the family members' Fear of surgery, economic problems, uncertainty about surgery, complications after anesthesia, postoperative complications, and fear of death were the factors of anxiety.

In addition, in an emergency crisis, anxiety of the patient's family increases the patient's anxiety and has a bad influence on the patient's adaptation or recovery. On the other hand, the positive and cooperative attitudes of the patient's family play a role in reducing the patient's anxiety and helping the patient to adapt appropriately. Therefore, the nurse should prepare an intervention plan that reduces the anxiety about the operation of the patient family. The emotional support of the family reduces the anxiety and emotional disturbances, while the low family cohesion and the lack of communication increase the psychological symptoms such as anxiety (Ryu, 2005). Patient Family One of the important parts of nursing interventions is to help them focus on patient care by reducing their anxiety before family anxiety appears. A study of family anxiety (McEwen, et al, 007) Anxiety was reduced when videotapes were used to provide information about surgery, anesthesia, and recovery to the patient's family. Therefore, it is necessary to identify the factors of family anxiety before the family anxiety occurs and to help them to solve it. According to Lesk (2002), the patient's family experiences the disruption of the family system and causes anxiety about fear of death, unexpected outcome, emotional anxiety, financial problem, role change, change of daily life, I experienced it. The intervention was divided into five areas. The intervention was provided to inform the patient about his / her condition, to provide comfort, to provide useful support, and to assure the reliability and cooperation between patient family and medical staff. In addition, Ivarsson (2005) suggested that careful attention to information, giving visual information, and providing information about the surgical procedure is important for patient family support by supporting the family of patients with cardiac surgery. Thus, family anxiety related to surgery can affect not only the family but also the patient, so effective family nursing-based intervention methods that can reduce the patient's family anxiety should be provided.

\section{Surgical patient's satisfaction with nursing needs}

In this study, we examined the relationship between family members 'perceptions of family members and family members' perceptions of family members. Nursing needs satisfaction is the degree of agreement between the need for ideal nursing practice and the actual practice of nursing practice that the subject believes necessary to maintain and recover health (Lee, 2006). The patient's family needs to be informed about the onset of anesthesia, the progress of the operation, the patient's condition during surgery, the expected time for surgery, the mid-explanation of the doctor if the operation time is long, In addition, it is necessary to provide information about the patient's condition during surgery, the progress of the operation, the expected time, the completion of 
the operation, and the operation progress (Hong Heejung, 2000). Leske, 2003) Patient families want to hear reports of real-time patient status, especially after surgery, to explain to the physician about the surgery. In a study of the satisfaction of nursing needs of family members of cancer patients according to the method of providing information about the progress of surgery (Lim Jung Soon, 2006), Several researchers explored the use of a nurse liaison to communicate information to the surgical patient family members (Lerman et al., 1994). The role of the nurse liaison was to provide information and help the family members cope with stress, anxiety, and feelings of uncertainty (Lerman et al., 1994).

In summary, efforts to continually study and improve patient and family nursing service satisfaction are indispensable elements in modern medicine, which is oriented toward holistic treatment. However, in view of the above literature that the convenience and nursing needs of the patient family are not sufficiently reflected in the current patient nursing care, All of these studies indicated the need for the human factor in communicating information related to the surgical patient and the creation of programs or media to improve these could be one possibility to improve communication of family of the surgery patient..

\section{Research Design}

\section{Research Method}

The purpose of this study was to investigate the effects of SMS information provided to family members of surgical patients on nursing needs satisfaction of patients' families by using a nonqualified control group non-synchronized design.

\begin{tabular}{|l|c|c|c|}
\hline \multicolumn{1}{|c|}{ Characteristics } & Pre test & Intervention & Post test \\
\hline Control Group & Oc1 & & Oc2 \\
\hline Experimental Group & Oe1 & X & Oe2 \\
\hline
\end{tabular}

Oc1, Oe1: general characteristics, trait \& state anxiety, nursing needs before the procedure Oc2, Oe2: state anxiety, nursing satisfaction post the procedure,

\section{Study subjects}

$\mathrm{X}$ : nursing information using the SMS

The purpose of this study was to investigate the family members of patients who underwent orthopedic surgery at $\mathrm{G}$ hospital in B city from April $1^{\text {st }}$ to June 30th on 2016. Subjects were selected carefully by following criteria: (1) Adults over 18 years of age (2) those who have a good command of language, who have no hearing or speech impairment, and are able to communicate (3) who understand the purpose of this study and agree to participate in the study. The subjects were 48 subjects as control group ( 24 subjects) and experimental group (24 subjects). The sample size was determined by the formula of Cohen (1988), the significance level of .05 power of .80 , and the effect size of .50 respectively.

\section{Research Tools}

\section{1) Anxiety measurement tool.}

In this study researcher used Spielberger's (1975) The State-Trait Anxiety Inventory translated into Korean by Kim and Shin (1978). The STAI consists for a 40 items self-evaluation questionnaire which includes separate measures of state and trait anxiety through four point Likert scale. The State-Anxiety scale consists of twenty statements that evaluate how respondents' feel about anxiety "right now, at this moment". The anxiety level was found by calculation of scores; the range of scores from 20-80, the higher the score indicating greater anxiety.

The Trait-anxiety scale: consists of twenty statements that assess how people "generally feel" about anxiety with four point scales: one (almost never), two (sometimes), three (often), and four (almost always). A rating of four indicates the presence of a high level anxiety and one indicates the absence of a high level anxiety for the homogeneity test of the two groups. The reliability of the trait anxiety was found to be Cronbach's $\alpha=.86$ in the study of Kim Jeong-taek and Shin Dong-gyun (1978), and Cronbach's $\alpha=.89$ in this study.

State anxiety measuring tool: The tool was scored from 1 to 4 for 'not at all', 'a little bit', 'usually yes', and 'very yes'. In the study of Kim Jung-Taek and Shin Dong-Kyun (1978), the reliability of state anxiety was Cronbach's $\alpha=.87$, and Cronbach's $\alpha=.94$ in this study

\section{2) Nursing needs and Satisfaction of family of surgery patients}

In this study used Perioperative Family Needs Questionnaire (PFNQ) scale to measure Nursing needs and Satisfaction which developed by Carmody et al. (1991). This tool consists of requesting information on the patient status of surgery, requesting treatment and nursing information, requesting emotional support, and requesting convenience facilities. This tool is composed of 4 points scale as measures the importance of needs through a Likert scale that varies from 1 (not important) to 4 (very important), and the higher the score, the 
higher the demand. Also it is distributed points between 20 -80 points. The same scale used Park's (2002) study shown the reliability of the instrument was Cronbach's $\alpha=.93$ where as Cronbach's $\alpha=.95$ in this study.

\section{Research process}

\section{1) Preliminary investigation}

The researchers noted and the list of the patients who underwent surgery and the scheduled time of operation at previous day of the surgery. Also researchers explained the purpose of the study to the patient's family who accompanied them and waiting outside the operating room on the day of surgery, who agreed to participate in the study. Both the control group and the experimental group were asked to complete the general characteristics and nursing need through questionnaires in the patient's family waiting room.

\section{2) Research assistant training}

The research assistant first checked the purpose of the study and the intention to participate to involve study from nurse working at the G Hospital surgery ward. Then nurses working in the operating room were trained about message transmission at the beginning, middle, and end of surgery.

\section{3) Experimental treatment.}

In the control group, the researcher provided information to the patient's family through the waiting list, operation progress, and completion of surgery at the waiting room outside the operating room based on progress of the surgery. Whereas the experimental group received additional information provided by the nurse based on the progress of surgery at the same time at each point directly from the surgical room by using SMS of the about the patient's condition. The contents of the surgery progress report used in this study were based on the needs of the patients who were interviewed by the family of surgery patients and the needs of nursing related to the surgery revealed in the literature review. The members involved during surgery were one physician, three nurses in the operating room, and one nursing professor. Surgery started. Table 1 summarizes the results of the intervention and the end of the operation.

$<$ Table 1> Contents of SMS service provided to experimental group

\begin{tabular}{|c|c|c|}
\hline Duration & TV screen & Message service contents \\
\hline Surgery begin & During surgery & $\begin{array}{l}\text { Ms/Mr ○ ○ ○ The surgery has begun. Patient status is currently good. All the } \\
\text { medical staff will do their best. }\end{array}$ \\
\hline Middle of surgery & During surgery & $\begin{array}{l}\text { Ms/Mr ○ ○ ○ surgical procedure is stable. } \\
\text { I will be able to tell you when you move to the recovery room after surgery. }\end{array}$ \\
\hline End of surgery & During surgery & $\begin{array}{l}\mathrm{Ms} / \mathrm{Mr} \bigcirc \mathrm{O} \bigcirc \text { is in good condition, } \\
---- \text { We are going to transfer to the recovery room. }\end{array}$ \\
\hline
\end{tabular}

\section{4) Post investigation}

After the surgery, the patient was transferred to the recovery room and then Family members in both groups filled out both portions of the State-Trait Anxiety Inventory measured according to the state anxiety and nursing needs in the patient's Family members at waiting room.

\section{Ethical Considerations:}

The study began with Institutional Review Board (IRB) approval obtained as Kaya IRB - 113 by the Research Ethics Review Board (IRB) of K University. All the participants were instructed about purpose and method of filling questionnaire, in addition ethical considerations were implemented for the subjects by stating that there is no disadvantage due to participation in the research and withdrawal is possible.

\section{Data analysis method}

The collected data were analyzed and analyzed using IBM SPSS 21.0. The demographic characteristics of the subjects were analyzed by descriptive statistics of mean and percentage, $\mathrm{x}^{2}$-test and t-test were used for homogeneity tests for general characteristics and pre-dependent variables. The difference of the post-dependent variables between the experimental group and the control group was analyzed by t-test. Reliability of the measurement tool was tested with Cronbach's $\alpha$.

\section{Homogeneity test of subject}

\section{Results}

\section{1) Homogeneity test for general characteristics of subjects}

Homogeneity test for the general characteristics of 24 subjects of experimental group and 24 subjects of control group shown in Table-2. There was no statistically significant difference between the two groups in 
terms of age, sex, religion, marital status, patient relationship, final education, surgical information experience, operative latency, stress perception, and trait anxiety in the experimental group and the control group.

<Table 2> General Characteristics of Experimental and Control Group

\begin{tabular}{|c|c|c|c|c|c|c|}
\hline \multirow{2}{*}{ Characteristics } & \multirow{2}{*}{ Categories } & Exp.(n=24) & Cont.(n=24) & n & \multirow{2}{*}{$x^{2}$ or $t$} & \multirow{2}{*}{$p$} \\
\hline & & $\mathrm{n}(\%)$ & $\mathrm{n}(\%)$ & n & & \\
\hline \multirow[t]{2}{*}{ Gender } & Male & $12(50.0 \%)$ & $8(33.3 \%)$ & 20 & \multirow{2}{*}{0.38} & \multirow{2}{*}{.190} \\
\hline & Female & $12(50.0 \%)$ & $16(66.7 \%)$ & 28 & & \\
\hline \multirow[t]{5}{*}{ Age (years) } & $20 \sim 29$ & $4(16.7 \%)$ & $8(33.3 \%)$ & 12 & \multirow{5}{*}{2.87} & \multirow{5}{*}{.209} \\
\hline & $30 \sim 39$ & $8(33.3 \%)$ & $8(33.3 \%)$ & 16 & & \\
\hline & $40 \sim 49$ & $8(33.3 \%)$ & $0(16.7 \%)$ & 8 & & \\
\hline & $50 \sim 59$ & $4(16.7 \%)$ & $6(25.0 \%)$ & 10 & & \\
\hline & $\geqq 60$ & $0(0.0 \%)$ & $2(8.3 \%)$ & 2 & & \\
\hline \multirow[t]{2}{*}{ Religion } & Yes & $15(62.5 \%)$ & $8(33.3 \%)$ & 23 & \multirow{2}{*}{0.24} & \multirow{2}{*}{.121} \\
\hline & No & $9(37.5 \%)$ & $16(66.7 \%)$ & 25 & & \\
\hline \multirow[t]{2}{*}{ Marital status } & Married & $16(66.7 \%)$ & $8(33.3 \%)$ & 24 & \multirow{2}{*}{0.22} & \multirow{2}{*}{.102} \\
\hline & Unmarried & $8(33.3 \%)$ & $16(66.7 \%)$ & 24 & & \\
\hline \multirow{4}{*}{$\begin{array}{ll}\text { Relationship } & \text { with } \\
\text { patient } & \end{array}$} & Parent & $4(16.7 \%)$ & $8(33.3 \%)$ & 12 & \multirow{4}{*}{2.83} & \multirow{4}{*}{.418} \\
\hline & child & $6(25.0 \%)$ & $10(41.7 \%)$ & 16 & & \\
\hline & Spouse & $8(33.3 \%)$ & $4(16.7 \%)$ & 12 & & \\
\hline & sibling & $6(25.0 \%)$ & $2(8.3 \%)$ & 8 & & \\
\hline \multirow[t]{3}{*}{ Education } & Middle school & $2(8.3 \%)$ & $2(8.3 \%)$ & 4 & \multirow{3}{*}{.25} & \multirow{3}{*}{.879} \\
\hline & High school & $4(16.7 \%)$ & $6(25.0 \%)$ & 10 & & \\
\hline & College & $18(75.0 \%)$ & $16(66.7 \%)$ & 34 & & \\
\hline \multirow{2}{*}{$\begin{array}{l}\text { Experience of } \\
\text { operation } \\
\text { information }\end{array}$} & Yes & $24(100.0 \%)$ & $16(66.7 \%)$ & 40 & \multirow[b]{2}{*}{.57} & \multirow[b]{2}{*}{.066} \\
\hline & No & $0(0.0 \%)$ & $8(33.3 \%)$ & 8 & & \\
\hline \multirow{2}{*}{$\begin{array}{l}\text { Experience of } \\
\text { Operative waiting }\end{array}$} & Yes & $18(75.0 \%)$ & $20(83.3 \%)$ & 38 & \multirow{2}{*}{.49} & \multirow{2}{*}{.615} \\
\hline & No & $6(25.0 \%)$ & $4(16.7 \%)$ & 10 & & \\
\hline \multirow[t]{3}{*}{ Stress perception } & very severe & $1(8.3 \%)$ & $6(50.0 \%)$ & 14 & \multirow{3}{*}{2.26} & \multirow{3}{*}{.072} \\
\hline & severe & $8(66.7 \%)$ & $5(41.7 \%)$ & 26 & & \\
\hline & moderate & $3(25.0 \%)$ & $1(8.3 \%)$ & 8 & & \\
\hline Trait anxiety & & $2.32 \pm .43$ & $2.41 \pm .38$ & 48 & 1.13 & 0.89 \\
\hline
\end{tabular}

\section{2) Homogeneity test of pre-dependent variables of experimental group and control group:}

The results shown in Table 3 that, there was no statistically significant difference in the state anxiety and nursing needs between the experimental group and the control group before the experiment. The average state of family anxiety was $54.50 \pm 9.43$ in the experimental group and $52.25 \pm 11.64$ in the control group $(\mathrm{t}=-$ $1.454, \mathrm{p}=.143)$. The family nursing demand was $3.32 \pm 0.56$ and $3.13 \pm 0.78$ in the control group, respectively $(\mathrm{t}=0.41, \mathrm{p}=0.76)$.

<Table 3> Homogeneity of pre-dependent Variables for Experimental and Control Group $(\mathrm{N}=48)$

\begin{tabular}{|l|c|c|c|c|}
\hline \multirow{2}{*}{ Dependent Variable } & Exp. Group $(\mathbf{n}=\mathbf{2 4})$ & Control Group $(\mathbf{n}=\mathbf{2 4})$ & \multirow{2}{*}{$\boldsymbol{t}$} & \multirow{2}{*}{$\mathbf{p}$} \\
\cline { 2 - 5 } & $\mathrm{M} \pm \mathrm{SD}$ & $\mathrm{M} \pm \mathrm{SD}$ & 0.56 & .143 \\
\hline State Anxiety & $54.50 \pm 9.43$ & $52.25 \pm 11.64$ & 0.41 & .076 \\
\hline Nursing Needs & $3.32 \pm 0.56$ & $3.13 \pm 0.78$ & $078)$ \\
\hline
\end{tabular}

\section{Hypothesis test}

The results of the hypothesis test to understand the effect of providing SMS information on the status anxiety and the satisfaction of the nursing needs of the patient's family in surgery are as follows.

\section{1) Hypothesis 1.}

The results shown in Table 4 that, the difference between the experimental group and the control group for 'the state anxiety score will be lower than that of the control group, the difference of the state anxiety scores before and after the intervention was $5.332 \pm 8.76$ in the experimental group and $7.58 \pm 10.89$ in the control group $(\mathrm{t}=-0.526, \mathrm{p}=.572)$, and the first hypothesis was rejected.

$<$ Table 4> Difference of the State Anxiety between Experimental and Control Group

\begin{tabular}{|l|c|c|c|c|}
\hline \multirow{2}{*}{\multicolumn{1}{c|}{ Intervention }} & Exp. Group (n=24) & Cont. Group (n=24) & \multirow{2}{*}{$\boldsymbol{t}$} & \multirow{2}{*}{$\boldsymbol{p}$} \\
\cline { 2 - 3 } & $\mathrm{M} \pm \mathrm{SD}$ & $\mathrm{M} \pm \mathrm{SD}$ & $48)$ & .143 \\
\hline pre test & $54.50 \pm 9.43$ & $52.25 \pm 11.64$ & 1.454 & .456 \\
\hline post test & $46.42 \pm 11.52$ & $52.67 \pm 8.78$ & -0.892 & .572 \\
\hline difference (pre-post) & $5.33 \pm 8.76$ & $7.58 \pm 10.89$ & -0.526 & .5 \\
\hline
\end{tabular}




\section{2) Hypothesis 2:}

The results shown in Table 5 that, the difference between the experimental group and the control group for 'the satisfaction of the nursing demand will be higher than the control group for whom the SMS about the progress status is not provided.

The second hypothesis was supported because there was a statistically significant difference $(t=5.482$, $\mathrm{p}<.001)$ in the difference of satisfaction score of nursing requirement after intervention between $3.32 \pm 0.42$ points in the experimental group and $2.43 \pm 0.61$ points in the control group.

<Table 5> Difference of the Need Satisfaction between Experimental and Control Group

\begin{tabular}{|l|c|c|c|c|}
\multicolumn{1}{c}{ Categories } & $\begin{array}{c}\text { Experimental Group } \\
(\mathbf{n = 2 4 )}\end{array}$ & $\begin{array}{c}\text { Control Group } \\
(\mathbf{n = 2 4 )}\end{array}$ & \multirow{2}{*}{$\mathbf{t}$} & \multirow{2}{*}{$\mathbf{p}$} \\
\cline { 2 - 5 } & $\mathrm{M} \pm \mathrm{SD}$ & $\mathrm{M} \pm \mathrm{SD}$ & & \\
\hline Patient's Information & $3.87 \pm 0.49$ & $2.51 \pm 0.57$ & 5.65 & $<.001$ \\
\hline Treat \& Care Information & $3.52 \pm 0.53$ & $2.73 \pm 0.68$ & 8.98 & .002 \\
\hline Emotional Support & $3.28 \pm 0.43$ & $2.29 \pm 0.78$ & 6.25 & $<.001$ \\
\hline Resources \& Facilities & $2.62 \pm 0.67$ & $2.25 \pm 0.76$ & 2.89 & .023 \\
\hline Total & $3.32 \pm 0.42$ & $2.43 \pm 0.61$ & 5.482 & $<.001$ \\
\hline
\end{tabular}

\section{Discussion}

The purpose of this study was to provide information on the progress of surgery through SMS to the family members of orthopedic surgery patients in G hospital, and to confirm the effect of state anxiety and nursing needs and satisfaction on the patient.

In the present study, the state anxiety scores before and after intervention were not statistically significant $(\mathrm{t}=-0.526, \mathrm{p}=.572)$, indicating that the difference of state anxiety scores before and after intervention was $5.332 \pm 8.76$ in the experimental group and $7.58 \pm 10.89$ in the control group. The results of this study were as follows. First, the nursing intervention was performed to reduce the anxiety of the patient's family. Lim (2006), stated there was no significant difference between the family who received the text transmission information and the family who received the information directly. Lee \& Lee (2013) showed that there was no significant difference in the anxiety of the family who received the information by short text service and the family that provided directly to the ICU. Lim, Suh, Chung (2010) also showed that there was no statistically significant difference in the state anxiety between the experimental group that received direct nursing information and the control group which did not receive information. However, in Park (2006) stated there was a significant difference in the state anxiety of cancer patient's family who received information and onset of care in the waiting room. Lee (2009), the experimental group receiving telephone intervention showed a lower level of state anxiety than the control group. In addition, Lee (2009) and Park (2002) showed that providing information about the surgery while being with the subjects significantly decreased state anxiety, it suggests that mediation of information provision and emotional support is necessary.

The satisfaction of nursing needs was investigated after intervention because it was not appropriate to perform before intervention. As a result of analyzing the satisfaction of nursing needs of family of surgical patients, satisfaction about patient's status was found to be high. This consistent with Carmody et al (1991) found that hearing information about the patient's condition, feeling that the caregivers are caring for the patient, in order of the family satisfaction is similar. The effect of family members who received SMS on the satisfaction of nursing needs was $3.32 \pm 0.42$ in the experimental group and $2.43 \pm 0.61$ in the control group $(t=5.482, P$ <.001). Park (2002) showed a high level of satisfaction with nursing care after providing information using preoperative pamphlets to patients with digestive organs cancer surgery, also Lim Jung Soon (2006) stated, there was no difference in the satisfaction of the nursing between the experimental group providing information using text service and the control group providing direct information. In the study of Na Yun Kyung (2008) The results showed that there was a difference in the satisfaction of nursing needs between the experimental group and the control group. This can be interpreted as the fact that the text service proved to be effective as direct information provision.Thus, intervention for the patient's family during surgery is an important factor to meet the needs of the patient's family who want to continuously listen to the patient's condition in the crisis of surgery and to reduce anxiety. It is an effective to mediate the nursing demand of the patient family directly by placing the nurse, however, it is an effective to fill the nurses to provide information directly, also difficulty in structure of information contents, mobilization of funds, nursing intervention, likewise there are some actual difficulties in applying it. However, indirect information using communication media such as SMS or E-mail can easily transmit structured information contents at a low cost, and also effective respectively. Therefore, in view of the simplicity and convenience of using SMS is an indirect means of providing information, and promoted as an effective information mediation method for the family of the surgical patients, and it can be expected in order to reduce anxiety of the patient's family and increase the nursing needs satisfaction. 


\section{Conclusion And Suggestions}

The purpose of this study was to provide information on the progress of surgery through SMS to the family members of orthopedic surgery patients in G hospital, and to confirm the effect of state anxiety and nursing needs and satisfaction on the patient. The study consists 24 subjects were an experimental group and 24 subjects in the control group. The research tool was the Perioperative Family Needs Questionnaire (PFNQ) developed by Park et al. (2002), it composed 20 items and Carmody et al. (1991) transforming the 45 items of State Trait anxiety scale for family members derived from Molter (1979) tool. The data were collected from the patient's family who accompanied them at the entrance of the operating room on the day of surgery and their general characteristics, temperament and state anxiety were examined. Nursing needs satisfaction was confirmed after intervention because it was not appropriate to confirm satisfaction before intervention. For the control group, the researcher provided information on the operation standby, operation progress, and completion of surgery through the status report of the waiting room according to the progress of the surgery. For the experimental group, related information was provided to the patient's family in real time directly from the operating room using SMS on the Internet. After the surgery the patients were moved to the recovery room, and the state anxiety and satisfaction of the nursing needs of the control group and the experimental group were measured at the entrance of the operating room. The collected data were statistically processed using SPSS 21.0, and the general characteristics of the subjects and the homogeneity of the experimental group and the control group were $\mathrm{x} 2$-test and t-test. Reliability was tested using Cronbach's $\alpha$. As a result, there was no significant difference $(\mathrm{p}=.572, \mathrm{p}=.572)$ between the state anxiety of the control group and the experimental group which received the letter about the progress of the operation through SMS. Results were significantly higher in the experimental group $(\mathrm{t}=5.482, \mathrm{p}<.001)$.

Based on the results of this study, the following suggestions are made. 1) In order to test the effectiveness of the information provided by the surgical progress information method developed in this study, further studies are required which differ in the timing and method of measurement. 2) Applying SMS to nursing interventions in various surgical situations (emergency surgery, high risk surgery) and reviewing the needs of family members of surgical patients.

\section{Financial Support:}

This work was supported by the 2016-KAYA University Research Grant.

\section{References}

[1] Benko, K. B. (2001). Getting the royal treatment. Modern Healthcare.39,28-32

[2] Boyle, H. J. (2005, August). Patient advocacy in the perioperative setting. AORN Journal, 82(2) 250-62

[3] Campbell, K. R. (2012). How families cope with the surgical waiting room. Retrieved from http://www. kevinmd.com/blog/ 2012/06/families-cope-surgical-waitingroom.html

[4] Carmody, S., Hickey, P., \& Bookbinder, M.(1991). Perioperative Needs of Families. Journal of AORN, 54(3), 561-567.

[5] Choi, J. H., Kim, J. A., Hong, N, S., Lee, B, H., Lee E. H.(2013). The effect of preparatory nursing information and information offered by short message service on anxiety and nursing satisfaction among family members of the intensive care unit in-patients. Journal of Korean clinical nursing research, 19(3), 383-394.

[6] Cvetic, E. (2011). Communication in the perioperative setting. Association of Perioperative Nurses, 94(3) 261-270. doi: 10.1016/j.aorn.2011.01.017

[7] Huang F, Shuo CL (2006). Reducing the anxiety of surgical patient's family's access short message service. AMIA Symposium Proceedings. 957

[8] Hong Hee-jung (2004). The effect of providing information on the progress of surgery using the status of patients in the waiting room of the surgery on mother's anxiety. Seoul National University.

[9] HJung, You-Jin (2006). The Effect of Preoperative Nursing Information on the Anxiety Level of Patients after Open Heart Surgery. Master's thesis, Korea University. http://mmedlib.korea.ac.kr/ SATKCT000017000019.

[10] Kim (2006). Effect of Information Protocol on Anxiety and Role Stress of Stroke Patient's Family that were Discharged from ICU. Dongeui University, Master thesis. Pg: p. 53-59

[11] ong Hee Jung and Lee Myeong Ae (2000). Increased patient parent and family satisfaction through information during surgery. Korean Journal of Medical QA 7 (1) 90-104

[12] Kloos JA, Daly BJ. (2008). Effect of a Family-Maintained Progress Journal on anxiety of families of critically ill patients. Crit Care Nursing Q 31(2): 96-107,

[13] Kun H.Y, SK (2009). A short message service by cellular phone in type 2 Michelle AF, Jill MC, Rachel YZR, Danielle PK, Joseph BR, Felizardo SC, Zeev NK. Children's desire for perioperative information. International Anesthesia Research Society 109(4)

[14] Kwon, S. H., \& Hwang, Y. J. (2004). A study of expectancy value on communication media based text-To compare mobile phone with internet messenger. Journal of Communication Science, 4 (1), 5-47.

[15] Landeweerd, J.A., Boumans, N.P.G (1988). Nurses' work satisfaction and feelings of health and stress in three psychiatric departments. International Journal of Nursing Studies 25, 225-234.

[16] Lee, S. Y. (2009). The effect of providing information regarding surgery progression using text message on anxiety in the family of surgery patients. Unpublished master's thesis, Chonbuk National University, Jeonju. 


\section{The Effect of Providing Surgical Progress Information Using SMS on Satisfaction of Nursing Needs}

[17] Leske, J. S. (1995). Effects of intraoperative progress reports on anxiety levels of surgical patient's family members. Applied Nursing Research 8(4): 169-73

[18] Leske, J. S. (1996). Intraoperative progress reports decrease family members' anxiety. AORN Journal, 64(3): 424-436. doi:10.1016/S0001-2092(06)63055-X

[19] Lim, J. S. (2006). Family needs satisfaction and state anxiety according to the method of offering information during cancer surgery. Unpublished master's thesis, Kyungpook National University, Daegu.

[20] Lim Jung Soon and Jung Bok Rye (2006). Nursing Satisfaction and Anxiety of Family with Cancer Patients according to Information Providing Method. Journal of Korean Oncology Nursing 7 (2): 162-167, 2007.

[21] MacDonald, K., Latimer, M., \& Drisdelle, N., (2006). Determining the impact of a surgical liaison nurse role in the pediatric operating room. Canadian Operating Room Nursing Journal,. 24(1): 7-14

[22] McEwen, A., Moorthy, C., Quantock, C., Rose, H., Kavanaqh, R.(2007). The Effect of Videotaped Preoperative Information on Parental Anxiety during Anesthesia Induction for Elective Pediatric Procedure. Paediatric Anesthesia, 17(6), 534-539.

[23] Muldoon, M., Cheng, D., Vish, N., DeJong, S., \& Adams, J. (2011). Implementation of an informational card to reduce family member anxiety. AORN Journal, 94(3): 246-53. doi: 10.1016/j.aorn.2011.01.016

[24] Munday, J., Kynoch, K., \& Hines, S. (2013). The effectiveness of information-sharing interventions as a means to reduce anxiety in families waiting for surgical patients undergoing an elective surgical procedure: A systematic review protocol. JBI Database of Systematic Reviews and Implementation Reports, 12(3):243-273.

[25] Na Y K (2008). The Effect of Surgical Patient Progression Information Using SMS on the Nursing Satisfaction and State Anxiety of Patient Family. Master Thesis, Ewha Woman's University Graduate School.

[26] Nursing. (2008). Clinical rounds: Giving families a call during surgery pays off. Nursing Center, 38(8):25.

[27] Paamilainen, E, Seppanen S., \& Astedt-Kurki, P. (2001). Family involvement in perioperative nursing of adult patients undergoing emergency surgery. Journal of clinical nursing, 10(2), 230-237.

[28] Park, J. I. (2002). The effect of provision of perioperative information for the laparotomy patient's families in waiting room. Unpublished master's thesis, Seoul National University, Seoul.

[29] Spielberger, C. D.(1972). Anxiety; Current Trends Theory and Research. New York; Academic Press Inc, 23-49.

[30] Titler, M. G. (2010). Translation science and context. Research and Theory for Nursing Practice, 24(1), 35-55. 